\title{
The PRDM9 KRAB domain is required for meiosis and involved in protein interactions
}

\author{
Yukiko Imai $^{1}$ • Frédéric Baudat $^{1}$ - Miguel Taillepierre ${ }^{2}$ - Marcello Stanzione $^{3}$. \\ Attila Toth ${ }^{3} \cdot{\text { Bernard de } \text { Massy }^{1} \text { (i) }}^{1}$
}

Received: 3 February 2017 /Revised: 3 May 2017 / Accepted: 4 May 2017 / Published online: 19 May 2017

(C) The Author(s) 2017. This article is an open access publication

\begin{abstract}
PR domain-containing protein 9 (PRDM9) is a major regulator of the localization of meiotic recombination hotspots in the human and mouse genomes. This role involves its DNA-binding domain, which is composed of a tandem array of zinc fingers, and PRDM9-dependent trimethylation of histone $\mathrm{H} 3$ at lysine 4. PRDM9 is a member of the PRDM family of transcription regulators, but unlike other family members, it contains a Krüppel-associated box (KRAB)-related domain that is predicted to be a potential protein interaction domain. Here, we show that truncation of the KRAB domain of mouse PRDM9 leads to loss of PRDM9 function and altered meiotic prophase and gametogenesis. In addition, we identified proteins that interact with the KRAB domain of PRDM9 in yeast two-hybrid assay screens, particularly CXXC1, a member of the COMPASS complex. We also show that $\mathrm{CXXC1}$ interacts with IHO1, an essential component of the meiotic double-strand break (DSB) machinery. As $\mathrm{CXXC1}$ is orthologous to Saccharomyces cerevisiae Spp1 that links DSB sites to the DSB machinery on the chromosome axis, we propose that these molecular interactions
\end{abstract}

Electronic supplementary material The online version of this article (doi:10.1007/s00412-017-0631-z) contains supplementary material, which is available to authorized users.

Bernard de Massy

bernard.de-massy@igh.cnrs.fr

1 Institut de Génétique Humaine UMR9002 CNRS-Université de Montpellier, 141 rue de la cardonille, 34396 Montpellier cedex 05, France

2 SEAT-TAAM CNRS Phenomin UPS44, 7 rue Guy Môquet, 94800 Villejuif, France

3 Faculty of Medicine at the TU Dresden, Institute of Physiological Chemistry, Fetscherstraße 74, 01307 Dresden, Germany involved in the regulation of meiotic DSB formation are conserved in mouse meiosis.

Keywords PRDM9 KRAB domain · Meiosis · Protein interactions $\cdot$ Recombination $\cdot \mathrm{CXXC} 1 \cdot \mathrm{IHO} 1$
Abbreviations
dpp Days post-partum
Y2H Yeast two-hybrid
FL Full length

\section{Introduction}

Meiotic recombination is initiated by programmed DNA double-strand breaks (DSBs), generated by SPO11 and accessory proteins (de Massy 2013). Meiotic DSBs are not randomly distributed within the genome but mostly occur at discrete regions, called hotspots (Baudat et al. 2013). Interestingly, the molecular mechanisms underlying the patterning of meiotic DSBs are quite distinct in different species with apparently two major pathways. One pathway, which has been extensively studied in yeast, is mainly guided by chromatin structure and the other, analyzed in detail in mice, is driven by the sequence-specific DNA-binding PR domain-containing protein 9 (PRDM9).

In Saccharomyces cerevisiae, meiotic DSBs preferentially occur at nucleosome-depleted regions in gene promoters (Ohta et al. 1994; Pan et al. 2011; Wu and Lichten 1994), where the level of trimethylation of histone $\mathrm{H} 3$ at lysine 4 (H3K4me3) is constitutively high (Borde et al. 2009). At a larger scale, DSB formation occurs in the context of a specific chromosome architecture that consists of chromatin loops anchored to a proteinaceous axis (Zickler and Kleckner 1999). 
DSB sites are preferentially located within chromatin loops, while several proteins that are required for DSB formation (Rec114, Mei4, and Mer2) localize on the chromosome axis (Blat et al. 2002; Panizza et al. 2011). Thus, DSB sites should interact with the chromosome axis before or at the time of DSB formation. In S. cerevisiae, this interaction is at least in part provided by Spp1 that directly interacts with both methylated H3K4 near DSB sites and the axis-localized protein Mer2 (Acquaviva et al. 2013; Sommermeyer et al. 2013).

In humans and mice, hotspots are specified by PRDM9, a meiosis-specific PRDM family protein (Baudat et al. 2010; Myers et al. 2010; Parvanov et al. 2010). PRDM9 includes several functional domains, such as a DNA-binding zinc finger array, a histone lysine methyltransferase PR/SET (PRDIBF1 and RIZ1 homology) domain, and a Krüppel-associated box (KRAB)-related domain. The PRDM9 zinc finger array is highly polymorphic both within and between species (Berg et al. 2010; Buard et al. 2014; Groeneveld et al. 2012; Kono et al. 2014; Oliver et al. 2009; Thomas et al. 2009). Strikingly, two congenic mouse strains in which the $\operatorname{Prdm} 9$ alleles have different zinc finger arrays show completely distinct sets of hotspots (Brick et al. 2012), generalizing the observation that hotspot localization is determined by the DNA-binding specificity of the zinc finger array (Grey et al. 2011). The PR/SET domain of PRDM9 catalyzes H3K4me3 in vitro (Eram et al. 2014; Hayashi et al. 2005; Koh-Stenta et al. 2014; Wu et al. 2013), and this post-translational modification is enriched at DSB hotspots in a PRDM9-dependent manner (Baker et al. 2014; Brick et al. 2012; Grey et al. 2011). However, $\mathrm{H} 3 \mathrm{~K} 4 \mathrm{me} 3$ is also enriched at promoters, but these sites are not used for meiotic DSB formation (Pratto et al. 2014; Smagulova et al. 2011). This implies that H3K4me3 is not sufficient for DSB site specification when PRDM9 is present. Indeed, in the absence of PRDM9, meiotic DSBs occur at transcription regulatory regions, such as promoters and enhancers (Brick et al. 2012). Thus, although the requirement of $\mathrm{H} 3 \mathrm{~K} 4 \mathrm{me} 3$ for DSB formation remains to be determined in mice, its presence near DSB sites, when PRDM9 is present or absent, is reminiscent of the DSB features described in S. cerevisiae. In the mouse, MEI4 and IHO1, two essential components for meiotic DSB formation, localize on unsynapsed chromosome axes where they are detected at the beginning of meiotic prophase when DSB formation takes place (Kumar et al. 2010; Stanzione et al. 2016). In addition, HORMAD1, a component of the chromosome axis that interacts with IHO1, is required for wild-type DSB levels (Daniel et al. 2011). This suggests that an interaction may be needed to bring PRDM9-bound sites where DSBs form (Lange et al. 2016) into proximity of DSB-promoting complexes on chromosome axes. Indeed, we have detected interactions between PRDM9 and potential axis sites compatible with this hypothesis (Grey et al. 2017) and several axis proteins interact with PRDM9 (Parvanov et al. 2017). Interestingly, PRDM9 harbors a KRAB-related domain that generally mediates protein-protein interactions (Lupo et al. 2013). This KRABrelated domain is present only in PRDM9 and PRDM7 among all PRDM family proteins (Hohenauer and Moore 2012), and its role is unknown. We hypothesized that it could be involved in the direct interaction between PRDM9 and a component (s) that enables the recruitment of hotspots to DSB proteins on the chromosome axis. To test this hypothesis, we generated a deletion in $\operatorname{Prdm} 9$ that leads to a truncation of this domain and showed that the PRDM9 KRAB domain is essential for meiosis progression, meiotic DSB repair, and synapsis in both female and male mice. In addition, we identified proteins that interact with the KRAB domain of mouse and human PRDM9 by yeast two-hybrid $(\mathrm{Y} 2 \mathrm{H})$ screening. The finding that CXXC1, the mammalian orthologue of S. cerevisiae Spp1, specifically interacts with the PRDM9 KRAB domain and also with IHO1 leads us to propose a role for PRDM9 $\mathrm{KRAB}$ in linking DSB hotspots to the chromosome axis.

\section{Results and discussion}

\section{The PRDM9 KRAB domain is essential for meiosis}

The PRDM9 KRAB domain includes subdomains A and B and is located between residues 23 and 86 of the protein. It shares strong similarity with the KRAB domain of SSX proteins, and conserved residues are mostly in the KRAB A domain that has a predicted alpha helical structure (Supplementary Fig. 1a) (Birtle and Ponting 2006). Conversely, the sequences of the KRAB domains of PRDM9 and SSX proteins are quite divergent from those of canonical KRAB domain proteins, such as KOX1 (Supplementary Fig. 1a). To determine its function in the mouse, we introduced a deletion in the KRAB domain by injecting Cas9 mRNA and a single-guide RNA that targets the 5' site of $\operatorname{Prdm} 9$ in C57BL/6(B6) $\times$ CBA F1 zygotes (see "Materials and methods") (Supplementary Fig. 1b, c). We identified a deletion of $26 \mathrm{bp}$ in the CBA allele of $\operatorname{Prdm} 9$ that has an additional zinc finger compared with B6 mice. This deletion led to a frameshift and a predicted protein that is translated from an internal AUG codon and lacks the first 42 amino acids, including several conserved residues of the KRAB A domain (Fig. 1a and Supplementary Fig. 1d). We detected this truncated protein (called PRDM9 $\Delta$ KB1 hereafter) in mouse testis protein extracts by western blotting (Fig. 1b). We noted that the migration of this PRDM9 $\Delta$ KB1 protein was faster than predicted since its predicted molecular weight is close to the one of the wild-type B6 PRDM9 control (95 and $97 \mathrm{kDa}$, respectively). This could suggest that PRDM9 $\triangle \mathrm{KB} 1$ is translated from more internal AUG codons and/or that post-translational modifications alter the migration. Moreover, PRDM9 $\Delta \mathrm{KB} 1$ protein level was lower than 
a

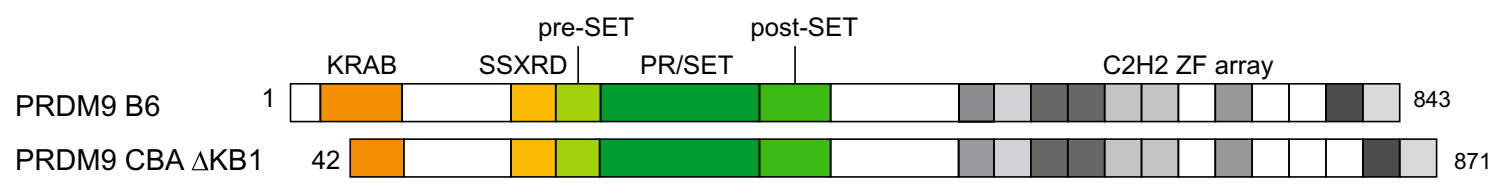

b

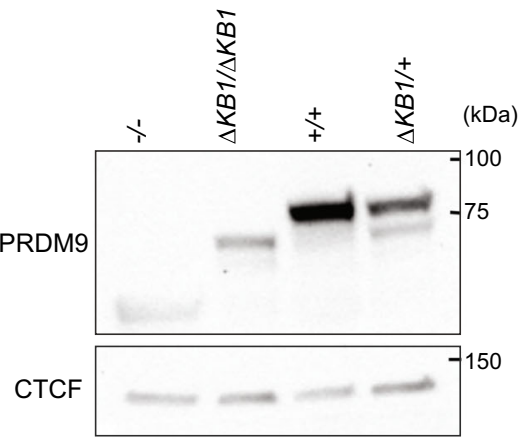

\begin{tabular}{cccccc} 
& \multicolumn{6}{c}{ Band intensities } \\
\cline { 2 - 6 } & \multicolumn{1}{c}{$\Delta K B 1 / \Delta K B 1$} & $+/+$ & top & bottom \\
\hline PRDM9 & 2298 & 5132 & 22617 & 10527 & 3782 \\
CTCF & 2092 & 3152 & 2343 & 4003 & 4003 \\
PRDM9/CTCF & 1.099 & 1.628 & 9.654 & 2.630 & 0.945 \\
\hline
\end{tabular}

C
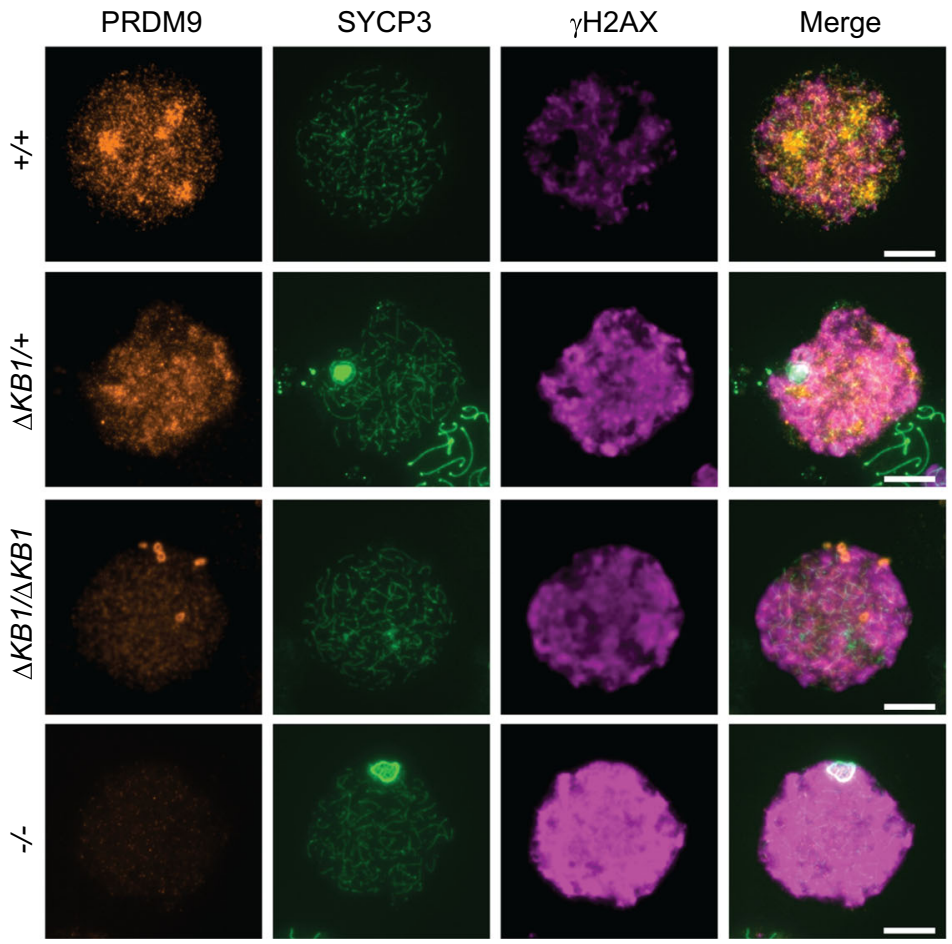

Fig. 1 A 26-bp deletion of the Prdm9 gene leads to production of an Nterminal truncated PRDM9 protein. a Schematic representation of the PRDM9 proteins expressed from the wild-type B6 allele and the CBA $\triangle K B 1$ allele of the $\operatorname{Prdm} 9$ gene. These two alleles have distinct zinc finger arrays. b Immunoblot of PRDM9 expression in $\operatorname{Prdm} 9^{-/-}$, $\operatorname{Prdm} 9^{\triangle K B 1 / \triangle K B 1}, \operatorname{Prdm} 9^{+/+}$(B6), and $\operatorname{Prdm} 9^{\triangle K B 1 /+}$ (heterozygous $\operatorname{Prdm} 9^{\triangle K B 1} / \operatorname{Prdm} 9^{\text {Dom2 }}$ from B6) testes at $13 \mathrm{dpp}$. Each lane was loaded with $100 \mu \mathrm{g}$ of testis protein extracts. The same membrane was stained with an anti-CTCF antibody as loading control. The predicted molecular weights of PRDM9 B6 and PRDM9 $\triangle$ KB1 are 97 and $95 \mathrm{kDa}$, respectively. Both proteins migrate faster than predicted. The right panel reports signal intensities in arbitrary units of each band

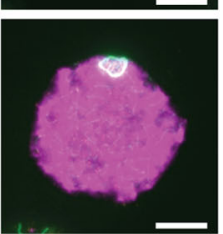

(PRDM9, CTCF and the top and bottom PRDM9 bands in $\triangle \mathrm{KB} 1 /+$ ) and the ratio of intensities between PRDM9 and CTCF (PRDM9/ CTCF). c Immunofluorescent analysis of PRDM9, SYCP3 (meiotic chromosomes axial elements marker), and $\gamma \mathrm{H} 2 \mathrm{AX}$ (DSB formation marker) expression in chromosome spreads of $\operatorname{Prdm} 9^{+/+}$(B6), $\operatorname{Prdm} 9^{\triangle K B 1 /+}$ (heterozygous $\operatorname{Prdm} 9^{\Delta K B 1} / \operatorname{Prdm} 9^{\operatorname{Dom} 2}$ from B6), $\operatorname{Prdm} 9^{\triangle K B 1 / \triangle K B 1}$, and $\operatorname{Prdm} 9^{-/}$spermatocytes at leptonema. Within one genotype, intensity of $\gamma \mathrm{H} 2 \mathrm{AX}$ can vary at leptonema and we did not detect consistent differences between genotypes. Chromosome spreads were prepared from 10-week-old $\left(\operatorname{Prdm} 9^{+/+}, \operatorname{Prdm} 9^{\Delta K B 1 /+}\right.$, and $\left.\operatorname{Prdm} 9^{\triangle K B I / \triangle K B I}\right)$ or 5-week-old $\left(\operatorname{Prdm} 9^{-/-}\right)$mice. Scale bars $=10 \mu \mathrm{m}$ 
that of wild-type PRDM9 (5.9- to 2.9-fold) in both $\operatorname{Prdm} 9^{\triangle K B I / \triangle K B I}$ and $\operatorname{Prdm} 9^{\triangle K B I /+}$ protein extracts (Fig. 1b, right panel). Similarly, by immunofluorescence analysis in spread spermatocytes, we could observe that PRDM9 $\Delta K B 1$ was detected in the nucleoplasm but at a lower level, compared to wild-type PRDM9, at leptonema, the stage at which it is most abundant (Grey et al. 2017). The reduction of PRDM9 in $\operatorname{Prdm} 9^{\triangle K B 1 / \triangle K B 1}$ compared to wild type was from 1.3- to 3.4-fold in early or late leptonema depending on whether the signal from $\operatorname{Prdm} 9^{-/-}$was subtracted or not (Fig. 1c and Supplementary Fig. 2).

We identified both oogenesis and spermatogenesis defects in $\operatorname{Prdm} 9^{\triangle K B 1 / \triangle K B 1}$ mice. Histological analysis showed that ovary development was compromised with the absence of growing primary and primordial follicles in adult ovaries. Adult testes presented defects in spermatogenesis with the absence of haploid cells (both spermatids and spermatozoa) (Fig. 2a). Testis weight was also strongly reduced in $\operatorname{Prdm} 9^{\triangle K B 1 / \triangle K B 1}$ males (Fig. 2b). Conversely, we did not find any significant difference in spermatogenesis and testis weight in wild-type and $\operatorname{Prdm} 9^{\Delta K B I /+}$ testes. To specifically examine the progression through meiotic prophase, we analyzed spread spermatocytes and monitored DSB formation, DSB repair, and synapsis by detection of phosphorylated histone H2AX $(\gamma \mathrm{H} 2 \mathrm{AX}), \mathrm{RPA}$, and SYCP1, respectively. DSBs were formed abundantly in $\operatorname{Prdm} 9^{\triangle K B 1 / \triangle K B 1}$ leptotene and zygotene spermatocytes (Figs. 1c and 2c). However, spermatocytes never progressed to the normal pachytene stage where all autosomes are fully synapsed and sex chromosomes are incorporated into a $\gamma \mathrm{H} 2 \mathrm{AX}$-rich chromatin domain, called the sex body (arrows in Fig. 2d). Instead, at the most advanced stage, we detected one or several asynaptic autosomes (arrowheads) in addition to apparently fully synapsed chromosomes with fully condensed axes that are characteristic of the pachytene stage (Fig. 2d). High $\gamma \mathrm{H} 2 \mathrm{AX}$ levels were present on asynaptic autosomes and sex body formation was defective in these cells (Fig. 2d). We could still observe RPA foci at this pachytenelike stage in $\operatorname{Prdm} 9^{\triangle K B 1 / \triangle K B 1}$ spermatocytes which also were weakly stained with testis-specific histone H1t (Supplementary Fig. 3). In wild type, at a comparable stage of progression in meiotic prophase, spermatocytes positive for H1t display a reduced number of RPA foci (Supplementary Fig. 3). Thus, $\operatorname{Prdm} 9^{\triangle K B 1 / \triangle K B 1}$ spermatocytes maintain a high level of RPA foci due to DSB repair defects and/or arrest in meiotic prophase. These phenotypes are similar to those observed in $\operatorname{Prdm} 9^{-/-}$mice (Hayashi et al. 2005; Sun et al. 2015).

The role of PRDM9 in specifying meiotic DSB sites involves its binding to DNA motifs and is associated with methylation of H3K4 and H3K36 on adjacent nucleosomes (Baker et al. 2014; Brick et al. 2012; Buard et al. 2009; Grey et al. 2011, 2017; Powers et al. 2016; Smagulova et al. 2011), leading to DSB formation in the immediate vicinity of PRDM9-
Fig. $2 \operatorname{Prdm} 9^{\triangle K B I / \triangle K B 1}$ gonads show developmental defects associated with synaptic defects at prophase I. a Representative images of Periodic acid-Schiff-stained paraffin sections of 10 -week-old $\operatorname{Prdm} 9^{+/+}$, $\operatorname{Prdm} 9^{\triangle K B 1 /+}$, and $\operatorname{Prdm} 9^{\triangle K B 1 / \triangle K B 1}$ testes (scale bars $\left.=50 \mu \mathrm{m}\right)$ and hematoxylin-eosin-stained paraffin sections of 10 -week-old $\operatorname{Prdm} 9^{+/+}$, $\operatorname{Prdm} 9^{\triangle K B 1 /+}$, and $\operatorname{Prdm} 9^{\triangle K B 1 / \triangle K B 1}$ ovaries. Two mice for each genotype (except for $\operatorname{Prdm} 9^{\triangle K B 1 /+}$ ovaries) were analyzed. Scale bars $=500 \mu \mathrm{m}$. b Testes/body weight ratio in $\operatorname{Prdm} 9^{+/+}(n=5)$, $\operatorname{Prdm} 9^{\triangle K B 1 /+}(n=4)$, and $\operatorname{Prdm} 9^{\triangle K B 1 / \triangle K B 1}(n=8)$ mice. c Immunofluorescent analysis of RPA (DSB repair marker), SYCP3 (meiotic chromosomes axial elements marker), and $\gamma \mathrm{H} 2 \mathrm{AX}$ (DSB formation marker) in chromosome spreads of $\operatorname{Prdm} 9^{+/+}, \operatorname{Prdm} 9^{\triangle K B I /+}$, and $\operatorname{Prdm} 9^{\triangle K B I / \triangle K B 1}$ spermatocytes at zygonema. Scale bars $=10 \mu \mathrm{m}$. d Immunofluorescent detection of SYCP1 (synapsis marker), SYCP3 (meiotic chromosomes axial elements marker), and $\gamma \mathrm{H} 2 \mathrm{AX}$ (sex body and DSB formation marker) in chromosome spreads of $\operatorname{Prdm} 9^{+/+}$, $\operatorname{Prdm} 9^{\triangle K B 1 /+}$, and $\operatorname{Prdm} 9^{\triangle K B 1 / \triangle K B 1}$ spermatocytes at pachynema. Arrows indicate the sex body. Arrowheads indicate unsynapsed axes. Scale bars $=10 \mu \mathrm{m}$. e H3K4me3 enrichment at CBA hotspots in RJ2, $\mathrm{CBA}$, and CBA Prdm $9^{\triangle K B 1 / \triangle K B 1}$ testes. Hlx1 1.2, Sycplprom (promoter region of the Sycp1 gene), and Hlx1 sts6 were used as control loci. CBA hotspots are $G 17 b, C W 19 c$, and $C W 2 b$. H3K4me3 enrichment relative to input at each locus was normalized to the Hlx1 1.2 values. Data from two technical replicates of independent ChIP experiments (circles) and their average value (horizontal bar) are shown

bound sites (Lange et al. 2016). To analyze if PRDM9 methyltransferase activity is impaired in $\operatorname{Prdm} 9^{\triangle K B 1 / \triangle K B 1}$ mice, we monitored H3K4me3 enrichment at hotspots known to be specified by the $\operatorname{Prdm} 9$ CBA allele $(G 17 b, C W 19 c$, and $C W 2 b)$ on the basis of the enrichment in $\mathrm{H} 3 \mathrm{~K} 4 \mathrm{me} 3$ and DMC1 from previous studies (Baker et al. 2015a; Smagulova et al. 2016). Here, we found H3K4me3 enrichment at the $G 17 b, C W 19 c$, and $C W 2 b$ hotspots in testis chromatin from CBA but not from $\operatorname{Prdm} 9^{\triangle K B 1 / \triangle K B 1}$ mice (Fig. 2e).

We conclude that the KRAB domain is important for PRDM9 activity and that the phenotypes observed in $\operatorname{Prdm} 9^{\triangle K B 1 / \triangle K B 1}$ spermatocytes could be due to the lower level of the truncated protein and/or to a loss of its specific activities such as methyltransferase, DNA-binding, and/or protein interaction. This may lead to the absence of DSB formation at the potential binding sites for PRDM9. As $\gamma \mathrm{H} 2 \mathrm{AX}$ and RPA foci are still present in $\operatorname{Prdm} 9^{\triangle K B 1 / \triangle K B I}$ spermatocytes, we hypothesize that DSBs are formed in $\operatorname{Prdm} 9^{\triangle K B 1 /}$ ${ }_{\triangle K B 1}$ mice, possibly near transcription regulatory sites, such as $\mathrm{H} 3 \mathrm{~K} 4 \mathrm{me} 3$-enriched promoters and enhancers, as observed in $\operatorname{Prdm} 9^{-/-}$mice (Brick et al. 2012).

\section{Identification of PRDM9 partners}

The KRAB domain is involved in protein interactions and mediates transcriptional repression (Lupo et al. 2013). The domain present in PRDM9 is more closely related to that of SSX proteins than of canonical KRAB-C2H2 zinc finger proteins (Birtle and Ponting 2006). Notably, the atypical KRAB 
a

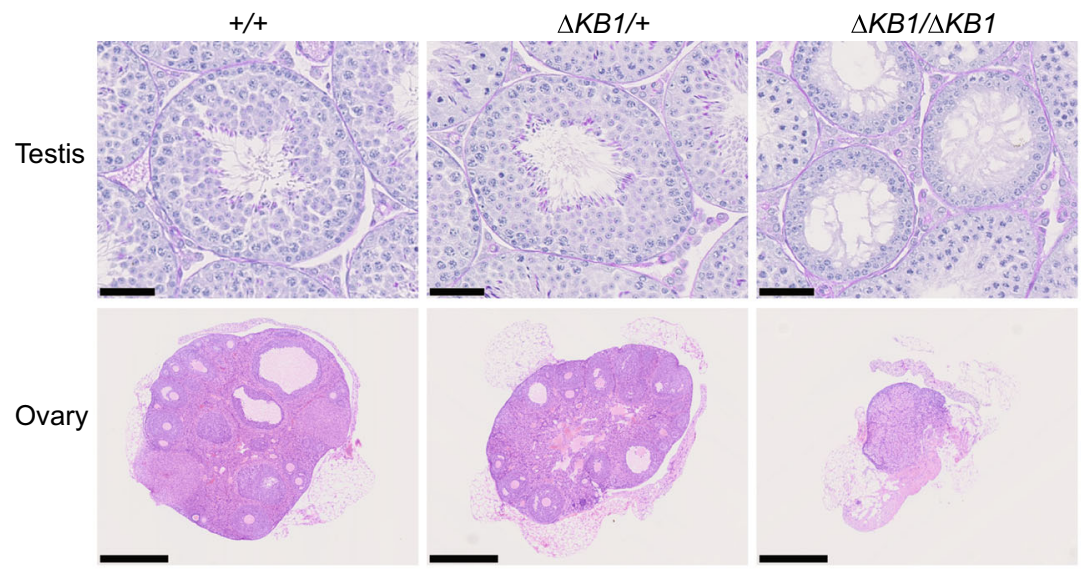

b

C
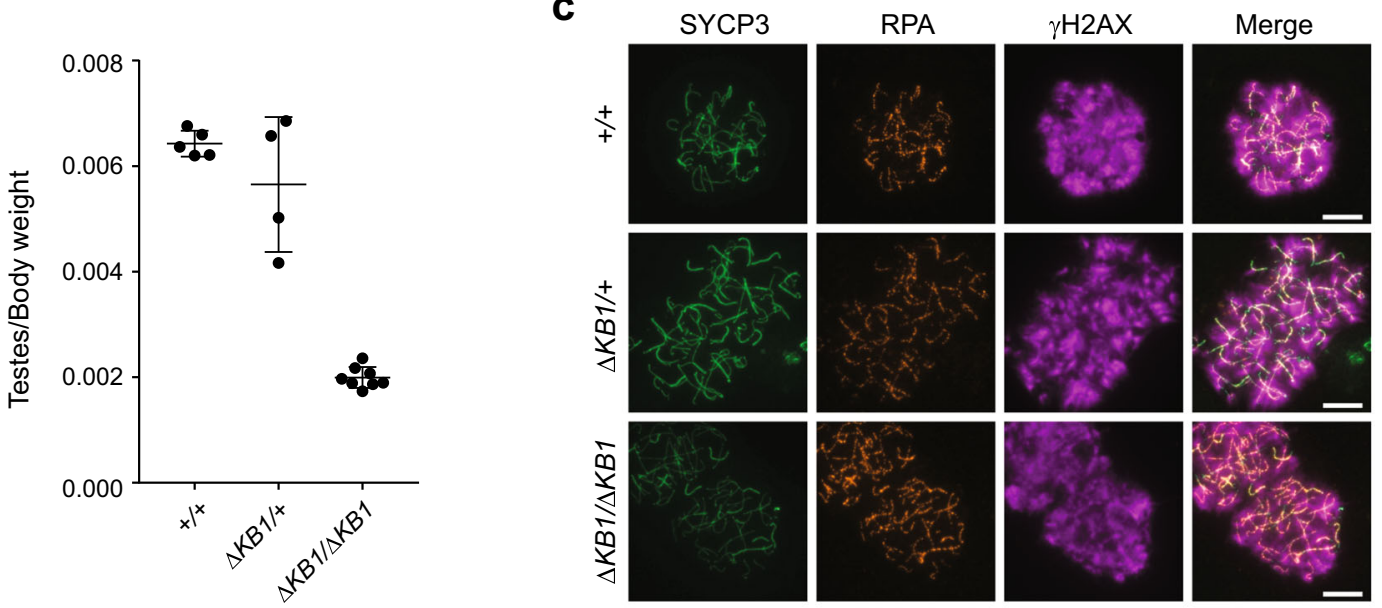

d

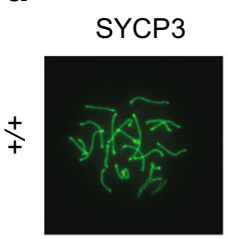

SYCP1
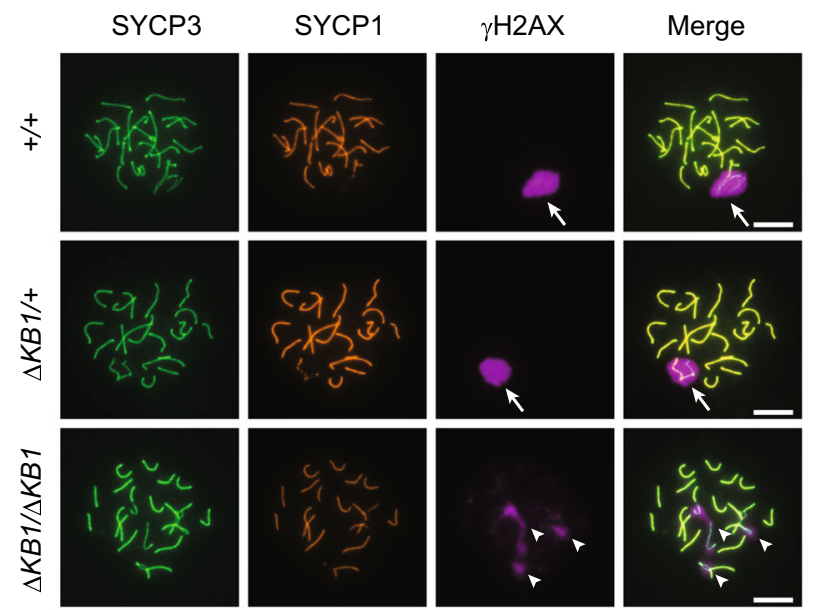

e

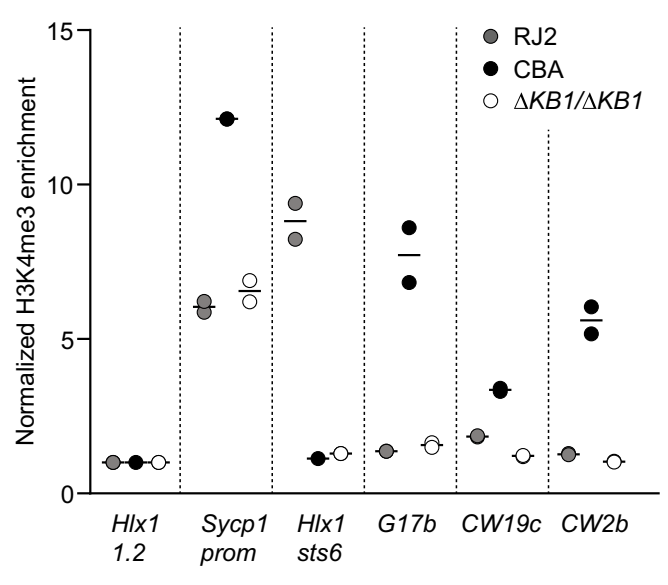

domains of SSX proteins harbor substitutions at KRAB A domain residues that are required for transcriptional repression and for the interaction with the transcriptional regulator TRIM28 (Lim et al. 1998). Accordingly, in vitro, human PRDM9 KRAB does not interact with TRIM28 (Patel et al. 2016). By Y2H assay, we found that TRIM28 did not interact with mouse PRDM9 KRAB (Supplementary Fig. 4a, b), whereas it interacted with the canonical KRAB domain of KOX1, as previously shown (Peng et al. 2000).

To identify potential partners, we performed two independent Y2H screens with mouse and human PRDM9 (see "Materials and methods," Supplementary Table 1). As no common protein was detected in these two screens, we assayed the interaction with PRDM9 of both mouse and 
human orthologues for 12 and 4 selected candidates from the mouse and human screens, respectively. This led to the conclusion that both mouse and human PRDM9 interacted with CXXC1, PIH1D1, CHAF1A, CEP70, FKBP6, IFT88, and MCRS1 from mouse and human, respectively (Fig. 3a and Supplementary Table 2). According to available mouse RNA-seq data sets (Margolin et al. 2014; Soh et al. 2015), the genes encoding these seven proteins are expressed in prepubertal testes, where the first wave of spermatogenesis takes place, as well as in embryonic ovaries, where oocytes are in meiotic prophase (Fig. 3b). Differently from $\operatorname{Prdm} 9$ and Spo11, these genes are expressed even before meiosis entry at 12.5 days post-coitum (dpc) during oogenesis (Fig. 3b). Taking advantage of the availability of antibodies against four of these proteins (CXXC1, PIH1D1, CEP70, and MCRS1), we could demonstrate their expression in testis extracts from prepubertal mice before meiosis entry ( 4 and 6 days postpartum, dpp), at later stages when spermatocytes proceed into meiotic prophase (9 to $15 \mathrm{dpp}$ ), and in adult mice (Fig. 3c).

To identify the PRDM9 region involved in these interactions, we generated various mouse PRDM9 expression plasmids that encoded one of its main domains: the KRAB domain, a region encoded by exon 5, the SSX Repressor Domain (SSXRD) that acts as a transcription repressor in SSX proteins (Lim et al. 1998), the pre-SET and SET domains involved in methyltransferase activity ( $\mathrm{Wu}$ et al. 2013), and the linker sequence between the SET domain and the zinc finger array (Supplementary Fig. 5). The zinc finger array was not included because the bait used for the $\mathrm{Y} 2 \mathrm{H}$ screening with the mouse cDNA library was PRDM9 without the zinc finger array. This analysis revealed that the KRAB domain was involved in all interactions (Table 1). In addition, the region encoded by exon 5 was involved in interactions with PIH1D1 and CHAF1A, whereas SSXRD weakly interacted with CXXC1 and CHAF1A. Therefore, the KRAB domain of PRDM9 is potentially involved in mediating interactions with various partners.

\section{CXXC1, the mouse orthologue of yeast Spp1, interacts with PRDM9 through its SET1-interacting domain}

We then investigated in more details the interaction between PRDM9 and CXXC1, because Spp1, the yeast orthologue of CXXC1, plays a major role in the localization of meiotic DSBs in S. cerevisiae (Acquaviva et al. 2013; Sommermeyer et al. 2013). By mapping the CXXC1 domains involved in the interaction with PRDM9 (Fig. 4a-c), we showed a robust interaction involving the SET1-interacting domain (SID) (Butler et al. 2008) and a weak interaction mediated by PHD2, a putative PHD with a poor match to the consensus sequence (Voo et al. 2000) (Supplementary Fig. 6a). Interestingly, these two domains are also important for CXXC1 interaction with the SETD1A and SETD1B complexes (Butler et al. 2008). We then showed that the deletion of the KRAB domain in PRDM9 $\triangle \mathrm{KB} 1$ strongly reduced the interaction with CXXC1C-terminal region (348-660) and abolished the interaction with CXXC1 SID (Fig. 4d, e).

\section{The interaction between CXXC1 and IHO1 suggests a role for CXXC1 in loop/axis interaction}

S. cerevisiae Spp1 interacts with Mer2 and mediates indirect interactions between the chromosome axis to which Mer2 is associated and DSB sites enriched for H3K4me3, where Spp1 can bind through its PHD finger (Acquaviva et al. 2013; Sommermeyer et al. 2013). The mouse IHO1 protein shares many properties with yeast Mer2 (Stanzione et al. 2016): they are both localized on the chromosome axis, are required for MEI4/REC114 axis association and for meiotic DSB formation, and interact with REC114 (Fig. 6a). Despite the low sequence similarity, IHO1 is a Mer2 homologue (HM Bourbon, personal communication) and, therefore, might interact with $\mathrm{CXXC1}$. Indeed, we detected a strong interaction between $\mathrm{CXXC1}$ and the $\mathrm{C}$-terminal domain of IHO1 (Fig. 5a-c). We also showed that the PHD2 of CXXC1 was sufficient for this interaction (Fig. 5d, e). As the Spp1-Mer2 interaction also involves the C-terminal region of Spp1 (Acquaviva et al. 2013) (Supplementary Fig. 6b), we searched for similarity between CXXC1 and Spp1 C-terminal regions and found four conserved residues in the PHD2 domain of CXXC1 (Butler et al. 2008) (Supplementary Fig. 6c).

However, we could not observe significant interactions between PRDM9, CXXC1, and IHO1 by co-immunoprecipitation of mouse testis extracts using various approaches. It is possible that these interactions cannot be detected in the high salt conditions required for PRDM9 extraction. Alternatively, they could be transient and/or involve only a fraction of nuclear proteins. Thus, on the basis of the interaction detected by the $\mathrm{Y} 2 \mathrm{H}$ assays, we propose that $\mathrm{CXXC1}$ may provide a link between PRDM9 sites and the chromosome axis (Fig. 6b). PRDM9 binding to its target genomic sites is associated with a local H3K4me3 enrichment on adjacent nucleosomes, predicted to be catalyzed by PRDM9 methyltransferase activity. We propose that CXXC1 is associated with these sites through the combined interaction with PRDM9 and H3K4me3, because the PHD1 of CXXC1 binds to methylated H3K4 (Eberl et al. 2013). The association of CXXC1 with IHO1, which interacts with REC114, will thus bring in proximity DSB sites and components essential for DSB formation (the potential IHO1-REC114-MEI4 complex). Whether this process is driven by diffusion and stabilization of interactions or by an active mechanism such as loop extrusion remains to be determined. SPO11-TOPOVIBL, the catalytic complex for DSB formation (Robert et al. 2016), may be initially associated with PRDM9 or with the IHO1-REC114-MEI4 complex. In any case, DSBs will be induced within the chromosome axis. We further hypothesize that in this context, CXXC1 does not interact with the SET1-COMPASS complex near 
a

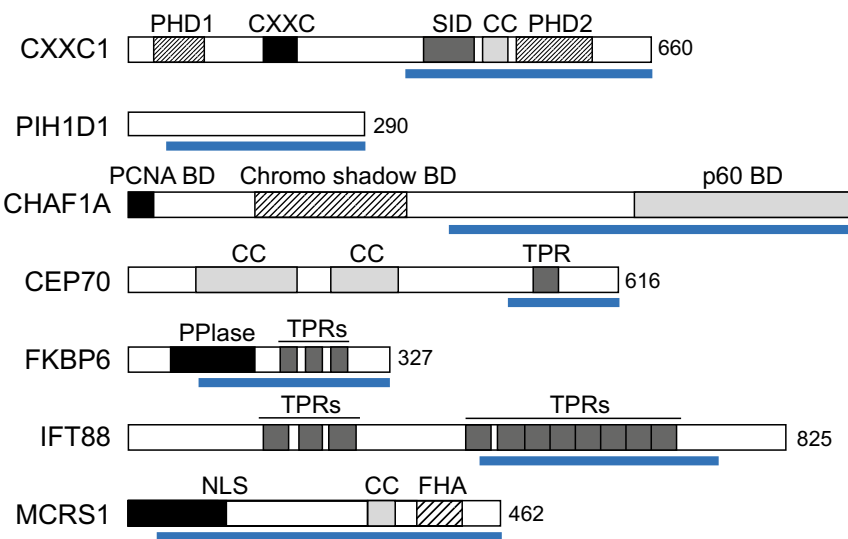

C

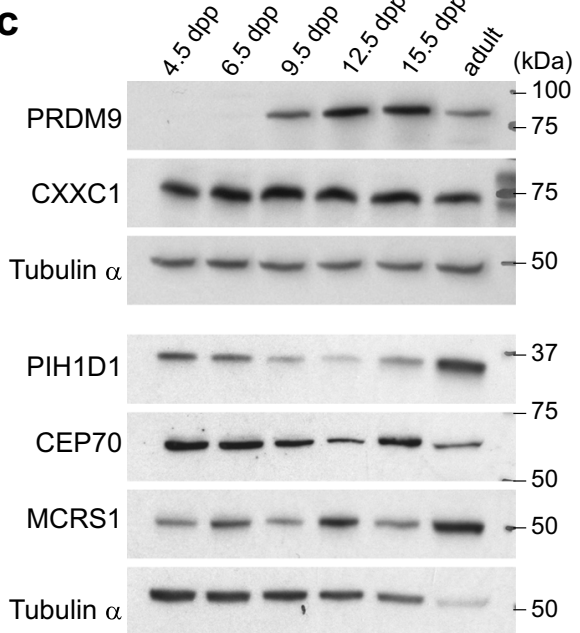

b

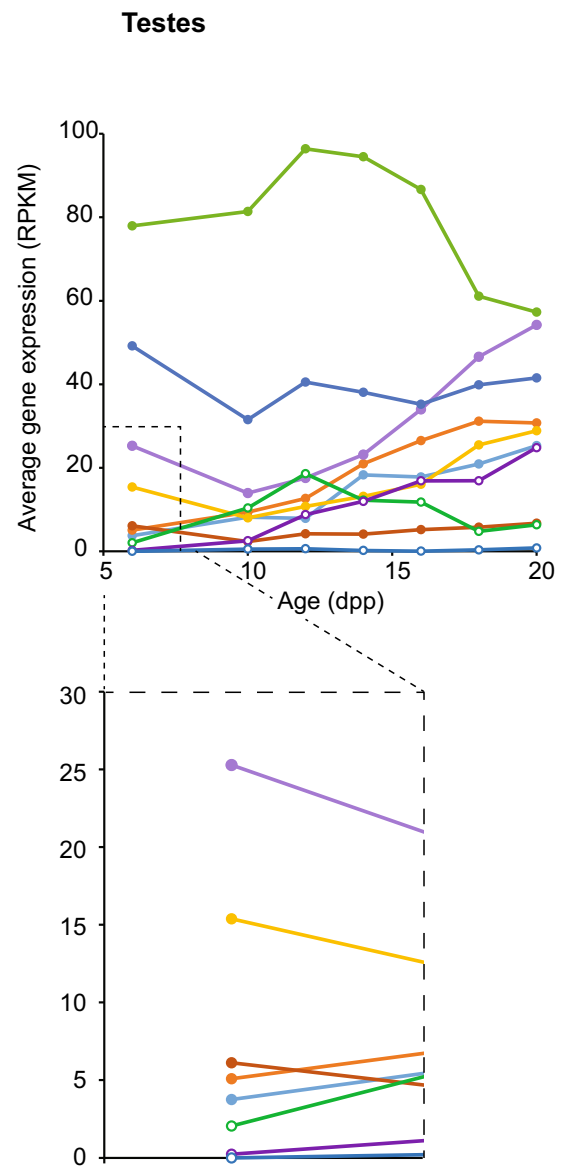

Fig. 3 Identification of interacting partners of PRDM9 by $\mathrm{Y} 2 \mathrm{H}$ screening. a Schematic representation of the domain structure of seven PRDM9-interacting proteins identified by $\mathrm{Y} 2 \mathrm{H}$ screening. The prey fragments identified in the screens are shown as blue bars underneath each protein. The length (number of amino acid residues) of each fulllength protein is indicated on the right. $\mathbf{b}$ RNA expression of the PRDM9interacting proteins in mouse testes (left) and ovaries (right) during meiosis. Data were extracted from RNA-seq data in Margolin et al. (2014) and Soh et al. (2015)). The average gene expression is shown in

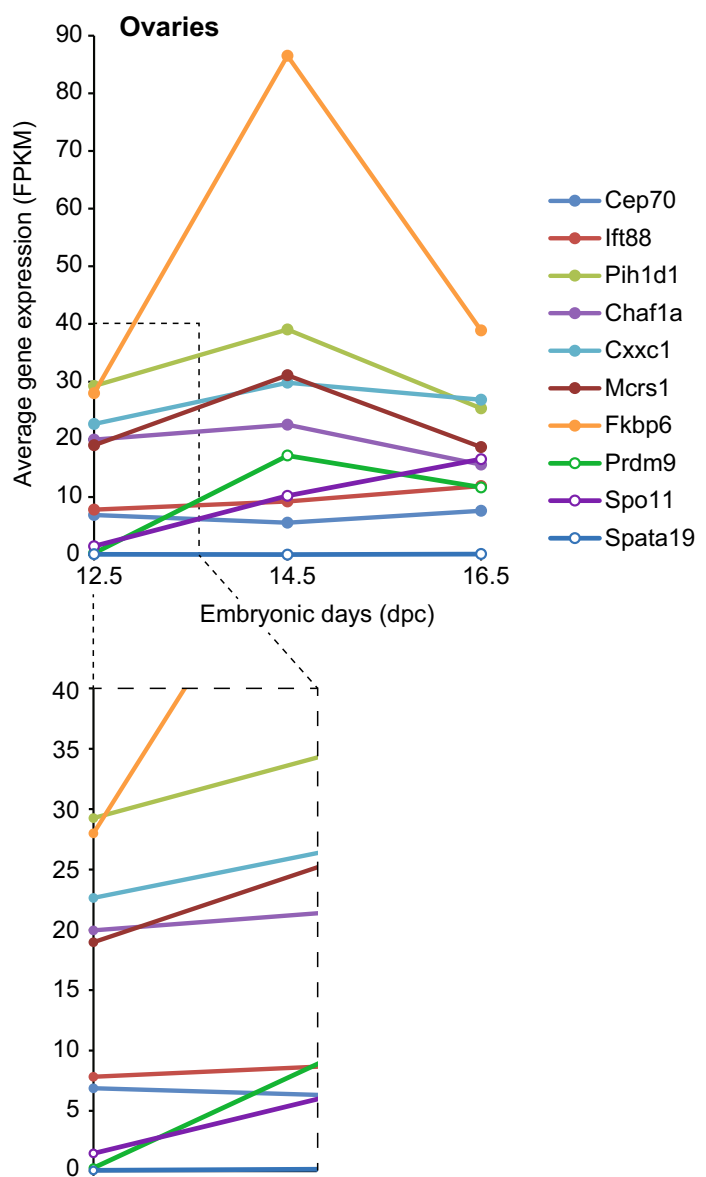

reads per kilobase per million of reads (RPKM) and fragments per kilobase of transcript per million mapped read (FKPM) for testes and ovaries, respectively. Zoomed-in views of the dashed line boxes are shown below. Spo11 and Spata19 expression were used as positive and negative controls, respectively. c Western blot analysis of PRDM9, CXXC1, PIH1D1, CEP70, and MCRS1 expression in whole testis extracts from 4.5, 6.5, 9.5, 12.5, and $15.5 \mathrm{dpp}$ and adult mice. Each lane was loaded with $50 \mu \mathrm{g}$ of testis protein extracts. Tubulin $\alpha$ was used as internal control 
Table 1 Mapping of interacting domains of PRDM9 by yeast two-hybrid assay

\begin{tabular}{|c|c|c|c|c|c|c|c|c|c|}
\hline & & & \multicolumn{7}{|c|}{ Gal4 BD-PRDM9 } \\
\hline & & & FL & $\mathrm{KRAB}^{\mathrm{a}}$ & Exon 5 & $\mathrm{SSXRD}^{\mathrm{a}}$ & Pre-SET & $\begin{array}{l}\mathrm{PR} / \mathrm{SET} \\
\mathrm{Y} 357 \mathrm{~F}^{\mathrm{a}}\end{array}$ & Linker \\
\hline \multirow[t]{8}{*}{ Gal4 AD } & $\mathrm{CXXC1}$ & $348-660$ & +++ & +++ & - & + & - & - & - \\
\hline & MCRS1 & FL & +++ & ++ & - & - & - & - & - \\
\hline & PIH1D1 & $42-290$ & +++ & +++ & +++ & - & - & - & - \\
\hline & CHAF1A & $397-911$ & ++ & + & ++ & + & - & - & - \\
\hline & CEP70 & FL & ++ & ++ & - & - & - & - & - \\
\hline & FKBP6 & $85-327$ & ++ & +++ & - & - & - & - & - \\
\hline & IFT88 & FL & ++ & ++ & - & - & - & - & - \\
\hline & \multicolumn{2}{|c|}{ Empty vector } & - & - & - & - & - & - & - \\
\hline
\end{tabular}

Gal4 BD was fused to mouse full-length PRDM9 (FL) or domains shown in Supplementary Fig. 5. Gal4 AD was fused to full-length (FL) or fragments (indicated in positions of amino acid residues) of mouse orthologues of seven proteins

- no growth on - $\mathrm{LWH},+$ few colonies on - LWH, ++ normal growth on - LWH, +++ growth on both - LWH- and -LWHAd

${ }^{a}$ Amino-triazole was added to $-\mathrm{LWH}$ at $5 \mathrm{mM}$ when constructs with self-activation activity were tested

transcription start sites (TSS), which could result from limiting CXX1. Our observation that the interaction domain of CXXC1 with PRDM9 overlaps the SID of CXXC1 (Fig. 4) suggests a competition between SET1 and PRDM9 for interaction with $\mathrm{CXXC1}$ and therefore the formation of two alternative complexes. Consequently, CXXC1 may be titrated away from SET1 complex by PRDM9 and no DSB activity induced near TSS in the presence of PRDM9 (Fig. 6b). This competition may also explain phenotypes associated with changes in $\operatorname{Prdm} 9$ gene dosage and its partial haplo-insufficiency (Baker et al. 2015b; Flachs et al. 2012). As the CXXC1 interaction domain with IHO1 is distinct from the SID (Fig. S6), one could envision the formation of a complex involving PRDM9, CXXC1, and IHO1. In the absence of PRDM9, CXXC1 might interact with loci enriched in $\mathrm{H} 3 \mathrm{~K} 4 \mathrm{me} 3$ through its PHD1, as part, or not, of the SET1-COMPASS complex and with IHO1 (Fig. 6c). CXXC1 is also a DNA-binding protein with affinity for non-methylated CpGs (Lee et al. 2001) and is enriched at $\mathrm{CpG}$ islands (Thomson et al. 2010). This activity could contribute to stabilize its interaction in particular at $\mathrm{CpG}$ islands, whether these are enriched for $\mathrm{H} 3 \mathrm{~K} 4 \mathrm{me} 3$ or not, and thus together or independently from its interaction with $\mathrm{H} 3 \mathrm{~K} 4 \mathrm{me} 3$ and SET1-COMPASS. This would result in DSB formation at $\mathrm{H} 3 \mathrm{~K} 4 \mathrm{me} 3$-enriched sites, including many promoters and at enhancers, as observed in $\operatorname{Prdm} 9^{-/-}$mice (Brick et al. 2012) but also at $\mathrm{CpG}$ islands whether enriched for H3K4me3 or not as observed in dogs where Prdm9 is a pseudogene (Auton et al. 2013).

\section{Materials and methods}

\section{Mice}

A 26-bp deletion in the $\operatorname{Prdm} 9$ gene was generated by CRISPR/Cas9-mediated mutagenesis to produce the $\operatorname{Prdm} 9^{\triangle K B 1}$ allele. Cas9 mRNA and a single-guide RNA targeting the 5' site of Prdm9 (5'-TGAACACCAACAAG CTGGA-3') were injected in B6 $\times$ CBA F1 zygotes. A founder mouse with the $\operatorname{Prdm} 9^{\triangle K B 1}$ allele was backcrossed to B6. This mutation is associated with the CBA allele of $\operatorname{Prdm} 9$ that is called $\operatorname{Prdm} 9^{\operatorname{Dom} 3}$. B6 carry the $\operatorname{Prdm} 9^{\text {Dom } 2}$ allele. $\operatorname{Prdm} 9$ knockout $\left(\operatorname{Prdm} 9^{-/-}\right.$) (Hayashi et al. 2005), CBA/JRj (Janvier Labs), and RJ2 (Grey et al. 2011) and B6 mice were used as controls. All experiments were carried out according to the CNRS guidelines and approved by the ethics committee on live animals (project CE-LR-0812 and 1295).

\section{Preparation of testis protein extracts}

Adult or juvenile mouse testes were homogenized in extraction buffer (50 mM HEPES-Na pH 7.9, $400 \mathrm{mM} \mathrm{NaCl}, 1 \%$ Triton X, 4 mM DTT, proteinase inhibitor cocktail; Roche). After incubation at $4{ }^{\circ} \mathrm{C}$ for $30 \mathrm{~min}$, samples were sonicated at high power for five cycles ( $30 \mathrm{~s}$ on, $30 \mathrm{~s}$ off) with a Bioruptor ${ }^{\circledR}$ Standard apparatus (Diagenode). The soluble fraction was recovered by centrifugation at $14,500 \mathrm{rpm}$ for $15 \mathrm{~min}$. Protein concentration was determined with the Bio-Rad Protein Assay (Bio-Rad). 
a CXXC1

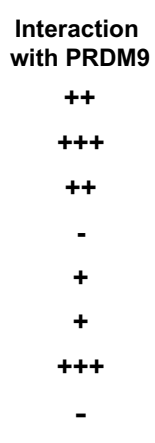

b

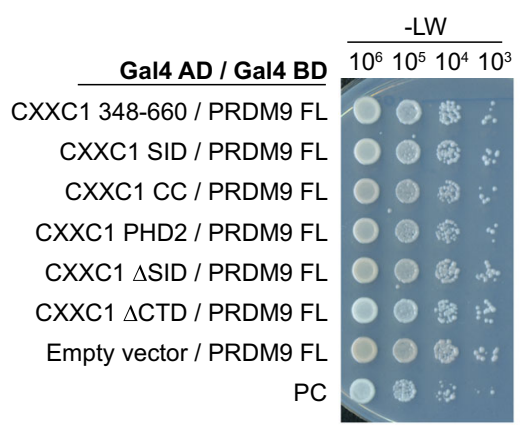

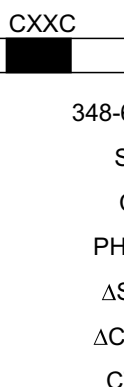

CTD

$\mathrm{CC}$

$\Delta \mathrm{SID}$

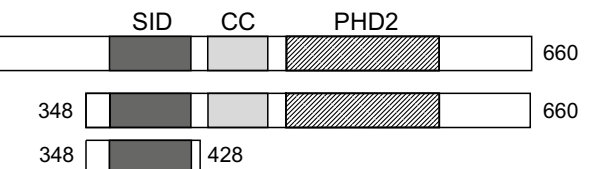

PHD2

TD

\begin{abstract}
348
\end{abstract}

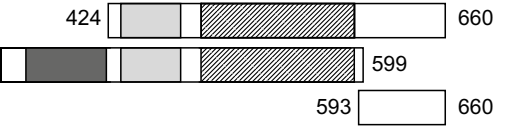

C

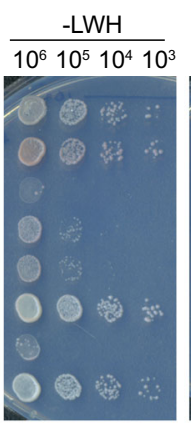

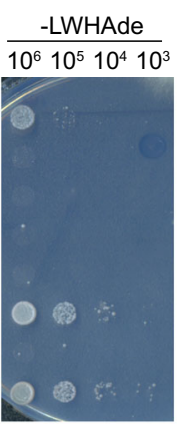

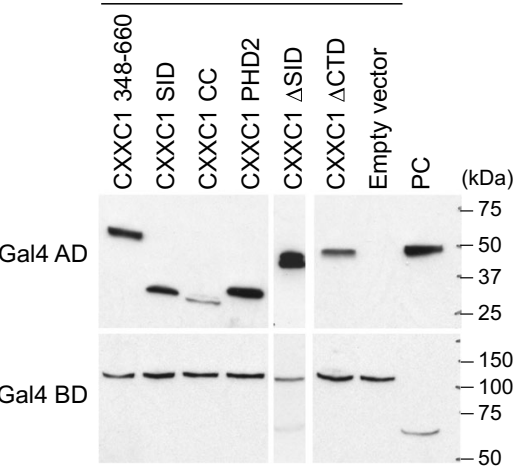

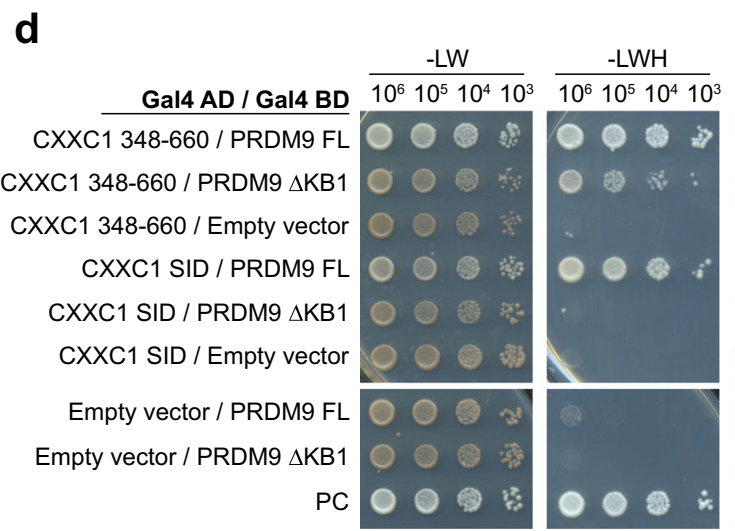

Fig. 4 The SET1-interacting domain $(S I D)$ of CXXC1 mediates the interaction with PRDM9. a Schematic representation of the mouse CXXC1 constructs used for domain mapping. Numbers correspond to the position of the amino acid residues from the N-terminus. PHD1 plant homeodomain 1, CXXC CXXC-type zinc finger, SID SET1interacting domain, $C C$ coiled-coil, $P H D 2$ plant homeodomain 2, CTD $\mathrm{C}$-terminal domain. Interactions with mouse PRDM9 detected by $\mathrm{Y} 2 \mathrm{H}$ assay are summarized on the right. Interactions with full-length CXXC1 $(F L)$ and CTD were examined by streaking on selective media (data not shown). b Mapping of the PRDM9-interacting domains in CXXC1 by

\section{Chromatin immunoprecipitation and quantitative polymerase chain reaction}

Four testes from 12- or 13-dpp mice were cross-linked with $1 \%$ formaldehyde/PBS for $10 \mathrm{~min}$, followed by incubation

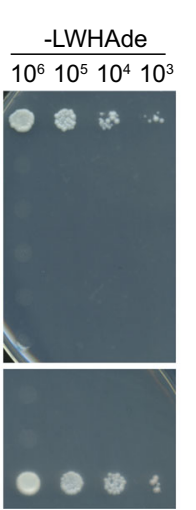

e

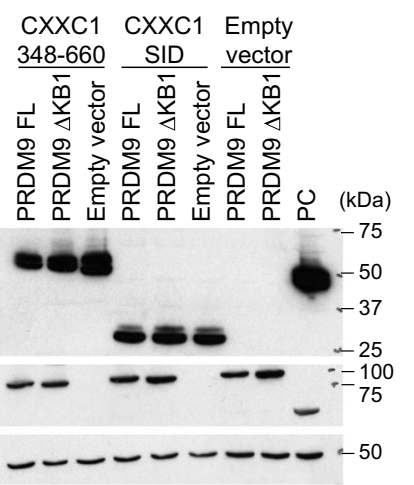

Y2H assay using truncated CXXC1 proteins. c Detection of Gal4 ADCXXC1 fusion proteins by western blotting in yeast extracts (upper panels). Full-length Gal4 BD-PRDM9 fusion protein, which is expected to be expressed at similar levels in the diploids tested here, was used as loading control (lower panels). d Y2H assay to test interactions between the indicated truncated $\mathrm{CXXC1}$ proteins and PRDM9 $\triangle$ KB1. e Detection of Gal4 AD-CXXC1 and Gal4 BDPRDM9 fusion proteins by western blotting of yeast extracts. Tubulin $\alpha$ was used as loading control. b-e $P C$ positive control

with $250 \mathrm{mM}$ glycine at room temperature for $5 \mathrm{~min}$. After washing in PBS, tubules were homogenized in a douncer. A single cell suspension was obtained by filtration with a $40-\mu \mathrm{m}$ cell strainer. Cell lysis and immunoprecipitation were performed as described in Houles et al. (2015) with the 
a
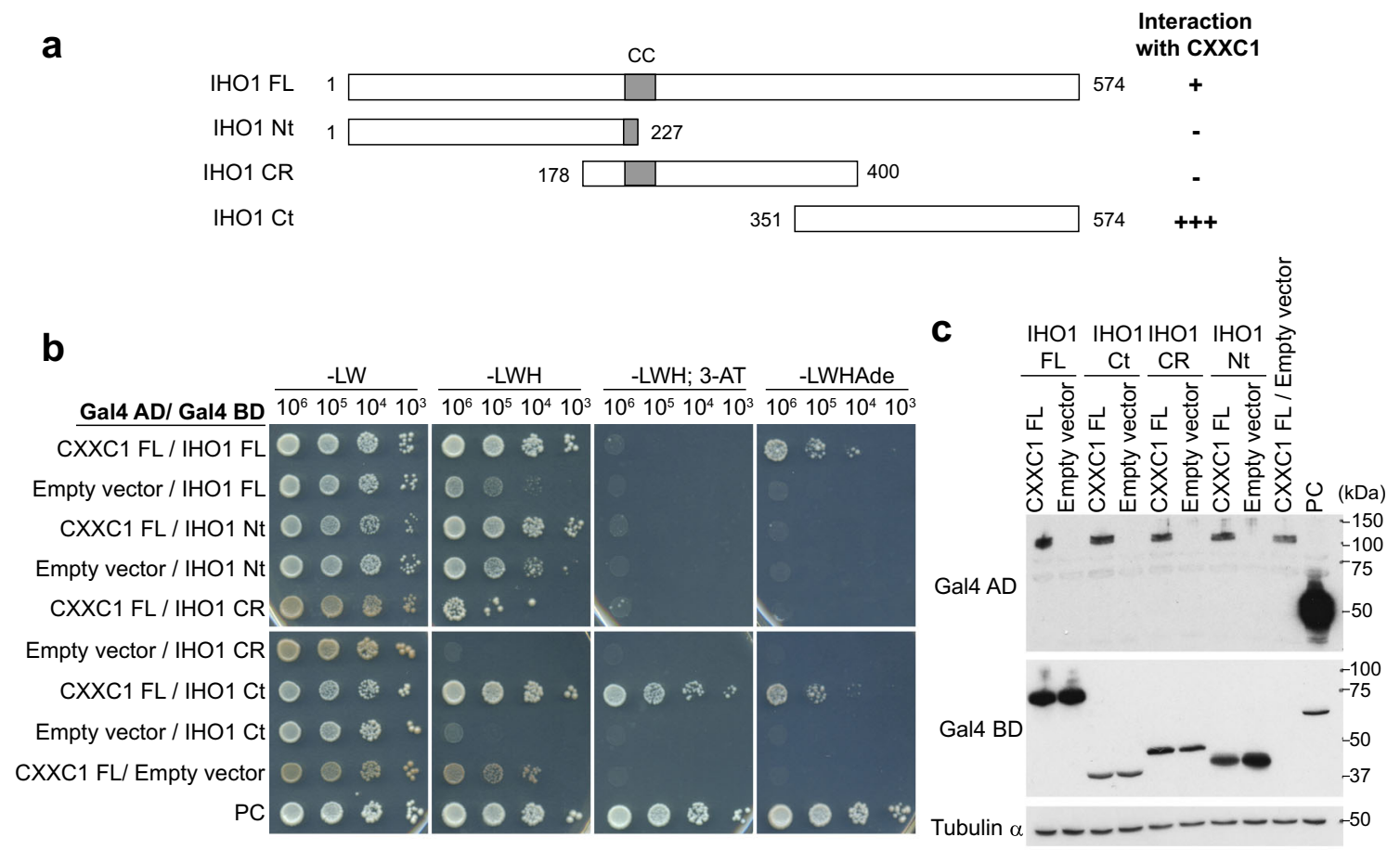

d

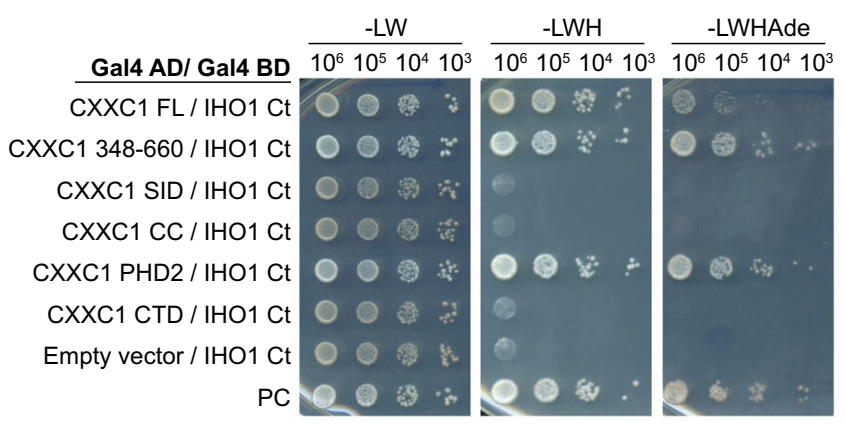

e

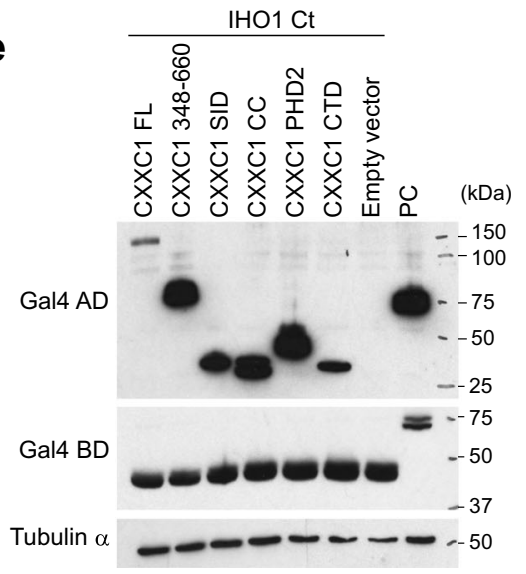

Fig. 5 CXXC1 interacts with IHO1. a Schematic representation of the mouse IHO1 constructs used for testing the interaction with mouse CXXC1. $C C$ coiled-coil, $C R$ central region, $C t$ C-terminus, $F L$ full length, $N t \mathrm{~N}$-terminus Numbers correspond to the positions of amino acid residues from the $\mathrm{N}$-terminus. b $\mathrm{Y} 2 \mathrm{H}$ assay to test the interaction between full-length $(F L) \mathrm{CXXC1}$ and full-length or truncated IHO1

following modifications: cells were lysed in $600 \mu \mathrm{l}$ lysis buffer containing $1 \%$ SDS; sonication was carried out with a Bioruptor $^{\circledR}$ Standard apparatus (Diagenode) at high power for four series of 10 cycles ( $30 \mathrm{~s}$ on, $30 \mathrm{~s}$ off); and chromatin was 10 -fold diluted in dilution buffer $(5 \mathrm{mM}$ Tris $\mathrm{pH} 8.0$, $140 \mathrm{mM} \mathrm{NaCl}, 0.5 \%$ Triton $\mathrm{X}-100,0.05 \%$ sodium deoxycholate, $0.5 \mathrm{mM}$ EGTA). For immunoprecipitation, $1 \mathrm{ml}$ of chromatin suspension was incubated with $20 \mu \mathrm{l}$ of Dynabeads ${ }^{\circledR}$ Protein A (Thermo Fisher Scientific) preincubated with $3 \mu \mathrm{g}$ of rabbit anti-histone H3 tri-methyl K4 antibody (Abcam, ab8580). proteins (see a). c Detection of Gal4 AD-CXXC1 and Gal4 BD-IHO1 fusion proteins by western blotting of yeast extracts. Tubulin $\alpha$ was used as loading control. d Mapping of the IHO1-interacting domain of $\mathrm{CXXC1}$ by $\mathrm{Y} 2 \mathrm{H}$ assay with truncated $\mathrm{CXXC1}$ proteins and $\mathrm{IHO} 1 \mathrm{Ct}$. e Detection of Gal4 AD-CXXC1 and Gal4 BD-IHO1 Ct fusion proteins by western blotting of yeast extracts. Tubulin $\alpha$ was used as loading control

Quantitative polymerase chain reaction (qPCR) was performed with FastStart SYBR Green Master (Roche) on a LightCycler ${ }^{\circledR} 480$ Instrument (Roche) and the following primers: G17b-F, 5'-CATGGACATGGAGACCTAACTG-3'; G17b-R, 5'-TCAGTGGAAGCTCAGAAAATGA-3'; CW19c-F, 5'-ACACATCTCTAAGATTATAGCTCAGCA3'; CW19c-R, 5'-CAAAGAACATGTAGTAAACA ATGAGGA-3'; CWb-F, 5'-CCTTAGGTATCCTATTGCAC TGCT-3'; and CW2b-R, 5'-GGATGGGGTTGAAC TAGCTG-3'. Primers for the Hlx1 1.2, Sycplprom, and Hlx1 sts6 sites have been reported previously (Buard et al. 2009). 
Fig. 6 A model of the meiotic function of PRDM9 and CXXC1 in mouse meiosis. a In

$S$. cerevisiae, Spp1 links hotspots to the Rec114-Mei4-Mer2 (RMM) complex through interactions with $\mathrm{H} 3 \mathrm{~K} 4 \mathrm{me} 2 / \mathrm{me} 3$ and Mer2 during meiosis (Acquaviva et al. 2013; Sommermeyer et al. 2013). The RMM complex axis localization is Hop1-dependent (Blat et al. 2002; Panizza et al. 2011). In this panel and in the following ones, only one sister chromatid is drawn. The other sister chromatid may or not be associated and involved in these interactions. b At leptonema in wild-type mouse meiosis, CXXC1 is not associated with SET1 but interacts with the KRAB domain of PRDM9 through its SID. In addition, CXXC1 interacts with H3K4me3 deposited by PRDM9 via PHD1 and can interact with IHO1 via PHD2. These interactions facilitate the recruitment of hotspots to the DSB machinery on chromosomal axes. c In Prdm9 knockout mice, $\mathrm{CXXC1}$ could be associated with promoters/CpG islands similarly to the localization reported in somatic cells (Thomson et al. 2010). This association may involve interaction with SET1, H3K4me3, and DNA-binding through the CXXC zinc finger. $\mathrm{CXXC1}$ and IHO1 interact leading to DSB formation near promoter/CpG islands (Brick et al. 2012) a

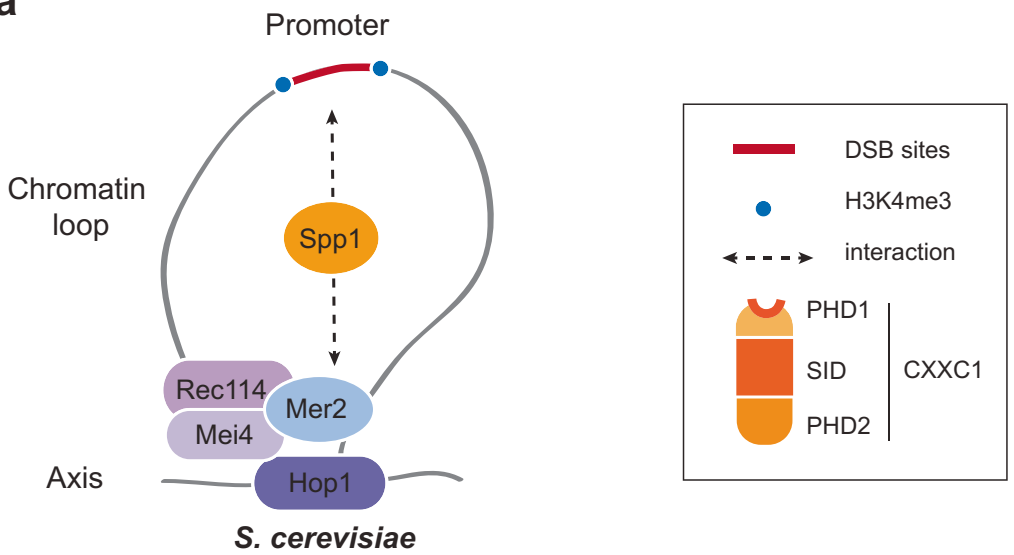

b

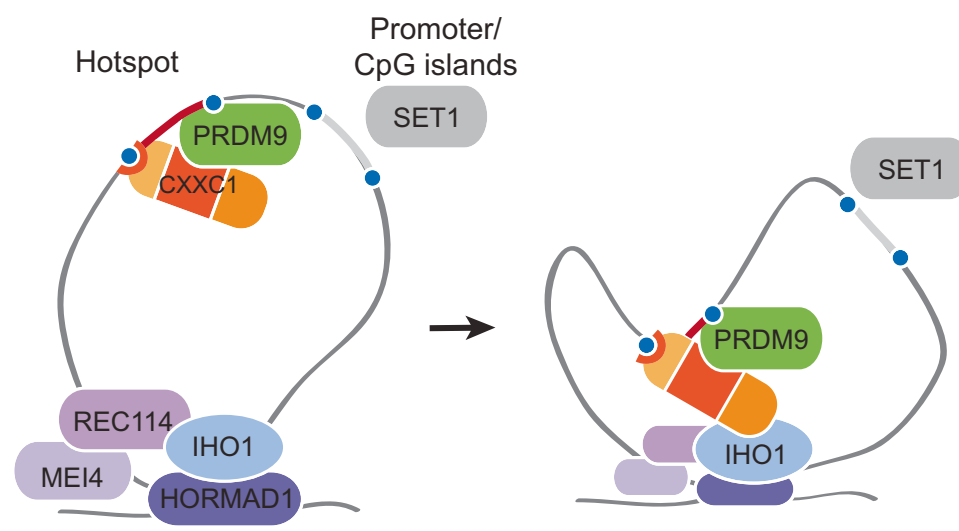

M. musculus: wild type

C

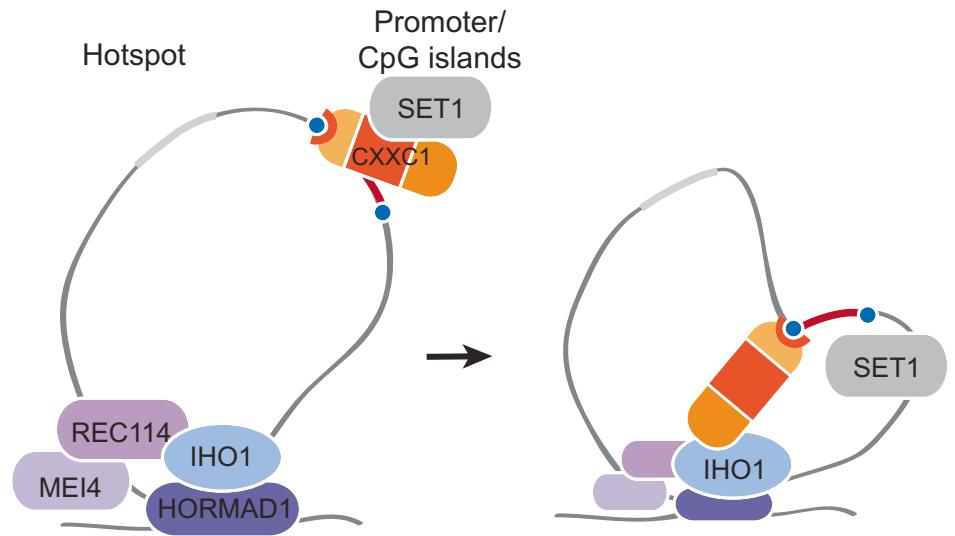

M. musculus: Prdm9 knockout
The $C W 19 c$ and $C W 2 b$ hotspots are located on chromosome 19 (GRCm38 coordinates; 19: 41,506,651-41,509,050) and 2 (2: 146,281,159-146,283,855), respectively. These sites were selected from strong peaks in DMC1 chromatin immunoprecipitation (ChIP)-seq data for the $\mathrm{C} 3 \mathrm{H}$ mouse strain (Smagulova et al. 2016), and their H3K4me3 enrichment was confirmed in the Watkins Star Line B (WSB) strain
(Baker et al. 2015a). As the CBA, C3H, and WSB mouse strains have the same $\operatorname{Prdm} 9^{\operatorname{Dom} 3}$ allele, hotspot locations are expected to be conserved in these three strains. $G 17 \mathrm{~b}$ (17: 78,648,623-78,652,485) was originally identified as a B6 hotspot (Brick et al. 2012), and then DMC1 and $\mathrm{H} 3 \mathrm{~K} 4 \mathrm{me} 3$ enrichment at this site was confirmed also in the $\mathrm{C} 3 \mathrm{H}$ and WSB strains, respectively (Baker et al. 2015a; 
Smagulova et al. 2016). Amplification data were analyzed with the LightCycler ${ }^{\circledR} 480$ SW 1.5.1 software (Roche).

\section{Spermatocyte chromosome spreads and immunofluorescence}

Spermatocyte chromosome spreads were prepared from 2- to 3 -month-old mice by the dry-down method (Peters et al. 1997). Spreads were incubated at room temperature overnight with the following primary antibodies and dilutions: rabbit anti-PRDM9 polyclonal, 1:50 (Grey et al. 2017); guinea pig anti-SYCP3 polyclonal, 1:1000 (Grey et al. 2009); mouse anti- $\gamma \mathrm{H} 2 \mathrm{AX}$ monoclonal (Millipore, 05-636), 1:10,000; rabbit anti-RPA $30 \mathrm{kDa}$ subunit polyclonal (gift from R. Knippers), 1:1000; guinea pig anti-histone H1t polyclonal (gift from M.A. Handel), 1:500; and rabbit anti-SYCP1 polyclonal (Abcam, ab15090), 1:400. Signals were visualized by incubation with goat anti-rabbit IgG Alexa Fluor 555 (Molecular Probes, A-21428), goat anti-guinea pig IgG Alexa Fluor 488 (Molecular Probes, A-11073), or antimouse IgG Alexa Flour 647 (Molecular Probes, A-31571) secondary antibodies at $37^{\circ} \mathrm{C}$ for $45 \mathrm{~min}$. After DAPI staining, slides were mounted using ProLong ${ }^{\circledR}$ Gold (Thermo Fisher Scientific). Digital images were captured with a complementary metal-oxide-semiconductor (CMOS) camera (ORCA-Flash4.0 .LT, Hamamatsu) attached to a Zeiss Axio imager 2 microscope (Zeiss). After data acquisition with the ZEN imaging software (Zeiss), images were processed with OMERO (OME). Spreads from two mice of each genotype were analyzed for each antibody. PRDM9 signal was quantified using the CellProfiler 2.2.0 software. A CellProfiler pipeline was designed for quantification of PRDM9 in regions of interest (ROIs): DAPI-positive regions of early and late leptotene nuclei. The PRDM9 background intensity was measured outside the ROI. Then, the PRDM9 signal total intensity of the ROI was calculated and corrected for background, by subtracting the product of the measured mean background intensity by the ROI area.

\section{Histological analysis}

Testes and ovaries from 9- to 10-week-old mice were fixed in Bouin's solution (Sigma) at room temperature overnight or for $5 \mathrm{~h}$, respectively. After dehydration and embedding in paraffin, 3- $\mu \mathrm{m}$ sections were prepared and stained with hematoxylin and eosin or with Periodic acid-Schiff. Image processing and analysis were carried out with the NDP.view2 software (Hamamatsu).

\section{Yeast two-hybrid screens}

The human $\mathrm{Y} 2 \mathrm{H}$ screen was performed by Hybrigenics Services, using the full-length human $\operatorname{Prdm} 9$ allele A cloned in the pB27 (LexA BD fusion) or pB66 (Gal4 BD fusion) vector, as baits. The prey library was derived from human adult testis cDNAs. In total, 119 million (pB27-PRDM9) and 90.4 million (pB66-PRDM9) of interactions were examined, and 23 and 358 clones were processed, respectively. The mouse $\mathrm{Y} 2 \mathrm{H}$ screen was performed by using mouse PRDM9 from Mus musculus domesticus without the zinc finger array ( $\triangle \mathrm{ZF}$, amino acids 2-512) cloned into pAS2-1 (Gal4 BD fusion) as bait. Mouse testis cDNAs were obtained from testis RNAs of 13- and 16-dpp mice and cloned in pGADT7 (Gal4 $\mathrm{AD}$ fusion) by using the BD Matchmaker Construction and Screening Kit (Clontech). In total, 170,000 interactions were examined, and 1115 positive clones were processed. cDNA sequences of positive clones were verified by PCR with the following primers: GADT7 $-5^{\prime} 5^{\prime}$-CTATTCGATGATGA AGATACCCCACCAAACC-3' and GADT7-3'5'-GTGA ACTTGCGGGGTTTTTCAGTATCTACGATT-3'. Among the 99 and 15 genes identified in the human and mouse screens, respectively (Supplementary Table 1), 16 candidates (4 and 12, respectively) with the strongest and specific interactions were tested again by $\mathrm{Y} 2 \mathrm{H}$ assay with both human (PRDM9 A allele) and mouse (PRDM9 ${ }^{\text {Dom2 }}$ allele) full length or truncated PRDM9 cDNA (Supplementary Table 2). Seven proteins from mouse and human, CXXC1, PIH1D1, CHAF1A, FKBP6, and MCRS1 (initially identified in the mouse screen) and CEP70 and IFT88 (initially identified in the human screen), showed interaction with PRDM9 from mouse and human, respectively.

\section{Yeast two-hybrid assay}

Most plasmids used in $\mathrm{Y} 2 \mathrm{H}$ assays were cloned in the pGADGH (Gal4 AD fusion) or pAS2-1 (Gal4 BD fusion) vector modified for the Gateway ${ }^{\circledR}$ Gene Cloning Technology (Invitrogen); pGADT7 clones from the mouse cDNA library were also used as prey constructs. Y187 and AH109 yeast haploid strains were transformed with Gal4 AD and BD fusion plasmids, respectively, by using a standard lithium acetate method. Yeast diploid clones were obtained by mating each Gal4 $\mathrm{AD}$ and Gal4 $\mathrm{BD}$ clone together on an YPD plate at $30^{\circ} \mathrm{C}$ and then streaking on SD medium lacking leucine and tryptophan $(-\mathrm{LW})$. Protein interactions were examined by streaking purified diploid clones on $-\mathrm{LW},-\mathrm{LW}$ lacking also histidine (-LWH), and - LW lacking also histidine and adenine (-LWHAd). For clones showing self-activation, $5 \mathrm{mM}$ 3-amino-1,2,4-triazol (3-AT) was added to - LWH plates. Interactions between $\mathrm{Gal} 4 \mathrm{AD}-$ and $\mathrm{BD}$ fusion proteins were evaluated based on cell growth after 3 days at $30{ }^{\circ} \mathrm{C}$. At least two clones were examined for all constructs. Cell growth of several clones was also examined by spotting serial dilutions of diploid cells $\left(10^{6}, 10^{5}, 10^{4}, 10^{3}\right.$ cells/spot $)$ on -LW, $-\mathrm{LWH}$, and -LWHAd plates. A diploid clone expressing Gal4 AD-REC114 and Gal4 BD-MEI4 was used as a 
control for positive interaction (referred to as positive control (PC)) (Kumar et al. 2010).

\section{Protein extraction from yeast cells}

Diploid yeast cells were pre-cultured in $5 \mathrm{ml}$ of SD liquid medium lacking leucine and tryptophan at $30{ }^{\circ} \mathrm{C}$ overnight. Cells were then diluted to $\mathrm{OD}_{600} \sim 0.25$ in $5 \mathrm{ml}$ of YPD medium. After incubation at $30^{\circ} \mathrm{C}$ for $4-6 \mathrm{~h}$, cells were collected at $\mathrm{OD}_{600} \sim 1.0$. Cell pellets were washed twice in cold water and then suspended in $200 \mu \mathrm{l}$ water. Cell lysis was performed by adding $200 \mu \mathrm{l}$ of $0.2 \mathrm{M} \mathrm{NaOH}$ and incubating at room temperature for $5 \mathrm{~min}$. After centrifugation at 12,000 rpm for $1 \mathrm{~min}$, pellets were dissolved in Laemmli buffer and then incubated at $95{ }^{\circ} \mathrm{C}$ for $5 \mathrm{~min}$. Protein extracts, equivalent to $0.5 \mathrm{OD}_{600}$ units, were used for immunoblotting. Extracts from diploid cells expressing Gal4 AD-REC114 and Gal4 BDMEI4 were loaded as positive control.

\section{Immunoblotting}

Protein extracts were separated on 7.5 or $10 \%$ Mini-PROTEIN TGX Precast Gels (Bio-Rad) and then transferred onto nitrocellulose membranes with the Trans-Blot Turbo Transfer System (Bio-Rad). The following primary antibodies and dilutions were used: rabbit anti-PRDM9 polyclonal (Grey et al. 2017), 1:500; rabbit anti-CTCF monoclonal (Cell Signaling Technology, $\mathrm{D} 31 \mathrm{H} 2), 1: 2000$; rabbit anti-CXXC1 polyclonal (Millipore, ABE211), 1:5000; rat anti-tubulin $\alpha$ monoclonal (Abcam, ab6161), 1:3000; rabbit anti-PIH1D1 polyclonal (Proteintech, AP19427), 1:5000; rabbit anti-CEP70 polyclonal (Abnova, PAB17658), 1:1000; mouse anti-MCRS1 polyclonal (Abnova, H00010445-B01P), 1:250; anti-Gal4 AD (Millipore, 06-283), 1:3000; and anti-Gal4 BD (Sigma, G3042), 1:2000. Signals were detected with the horseradish peroxidase (HRP)-conjugated secondary antibodies, donkey anti-rabbit IgG HRP (Jackson ImmunoResearch Laboratories), goat anti-rat IgG HRP (GE Healthcare), and sheep anti-mouse IgG HRP (GE Healthcare), and then visualized with SuperSignal West Pico Chemiluminescent Substrate (Thermo Fisher Scientific). ImageJ $1.49 \mathrm{~m}$ was used to quantify signal intensities of western blot images captured by ChemiDoc ${ }^{\mathrm{TM}}$ XRS+ Imager with the Image Lab 5.1 software.

\section{Protein sequence alignment}

Multiple protein sequence alignments were carried out using the T-Coffee Multiple Alignment program (http://www.ebi.ac. $\mathrm{uk} /$ Tools/msa/tcoffee) and the BLOSUM matrix. Alignment results were visualized with BoxShade (http://www.ch. embnet.org/software/BOX_form.html).
Acknowledgements We thank all laboratory members for discussion and input during this project. We thank the Réseau des Animaleries de Montpellier (RAM) mouse facility, the imaging facility Montpellier Resources Imagerie (MRI), the histology facility Réseau d'Histologie Expérimentale de Montpellier (RHEM), and the SEAT transgenic facility. We thank Florence Cammas for TRIM28/KOX1 clones, Katia Bouton for generating the mouse cDNA library, and Marie Goujon for help with the mouse $\mathrm{Y} 2 \mathrm{H}$ screen.

\section{Compliance with ethical standards}

Conflict of interest The authors declare that they have no conflict of interest.

Ethics approval All applicable international, national, and/or institutional guidelines for the care and use of animals were followed.

All animal experiments were carried out according to the CNRS guidelines and approved by the ethics committee on live animals (project CE-LR-0812 and 1295).

Informed consent Informed consent was obtained from all individual participants included in the study.

Funding BdM was funded by grants from the Centre National pour la Recherche Scientifique (CNRS) and the European Research Council Executive Agency under the European Community's Seventh Framework Programme (FP7/2007-2013 Grant Agreement no. [322788]). AT and MS were funded by the Deutsche Forschungsgemeinschaft (DFG; grants TO421/3-2, SPP1384:TO421/42, TO421/5-1, TO421/6-1, TO421/8-1 and 8-2). We thank the DIGS-BB program for supporting MS.

Open Access This article is distributed under the terms of the Creative Commons Attribution 4.0 International License (http:// creativecommons.org/licenses/by/4.0/), which permits unrestricted use, distribution, and reproduction in any medium, provided you give appropriate credit to the original author(s) and the source, provide a link to the Creative Commons license, and indicate if changes were made.

\section{References}

Acquaviva L, Szekvolgyi L, Dichtl B, Dichtl BS, de La Roche Saint Andre C, Nicolas A, Geli V (2013) The COMPASS subunit Spp1 links histone methylation to initiation of meiotic recombination. Science 339:215-218

Auton A et al (2013) Genetic recombination is targeted towards gene promoter regions in dogs. PLoS Genet 9:e1003984

Baker CL et al (2015a) PRDM9 drives evolutionary erosion of hotspots in Mus musculus through haplotype-specific initiation of meiotic recombination. PLoS Genet 11:e1004916

Baker CL et al (2015b) Multimer formation explains allelic suppression of PRDM9 recombination hotspots. PLoS Genet 11:e1005512

Baker CL, Walker M, Kajita S, Petkov PM, Paigen K (2014) PRDM9 binding organizes hotspot nucleosomes and limits Holliday junction migration. Genome Res 24:724-732

Baudat $\mathrm{F}$ et al (2010) PRDM9 is a major determinant of meiotic recombination hotspots in humans and mice. Science 327:836-840

Baudat F, Imai Y, de Massy B (2013) Meiotic recombination in mammals: localization and regulation. Nat Rev Genet 14:794-806

Berg IL, Neumann R, Lam KW, Sarbajna S, Odenthal-Hesse L, May CA, Jeffreys AJ (2010) PRDM9 variation strongly influences 
recombination hot-spot activity and meiotic instability in humans. Nat Genet 42:859-863

Birtle Z, Ponting CP (2006) Meisetz and the birth of the KRAB motif. Bioinformatics 22:2841-2845

Blat Y, Protacio RU, Hunter N, Kleckner N (2002) Physical and functional interactions among basic chromosome organizational features govern early steps of meiotic chiasma formation. Cell 111:791-802

Borde V, Robine N, Lin W, Bonfils S, Geli V, Nicolas A (2009) Histone $\mathrm{H} 3$ lysine 4 trimethylation marks meiotic recombination initiation sites. EMBO J 28:99-111

Brick K, Smagulova F, Khil P, Camerini-Otero RD, Petukhova GV (2012) Genetic recombination is directed away from functional genomic elements in mice. Nature 485:642-645

Buard J, Barthes P, Grey C, de Massy B (2009) Distinct histone modifications define initiation and repair of meiotic recombination in the mouse. EMBO J 28:2616-2624

Buard J, Rivals E, Dunoyer de Segonzac D, Garres C, Caminade P, de Massy B, Boursot P (2014) Diversity of Prdm9 zinc finger array in wild mice unravels new facets of the evolutionary turnover of this coding minisatellite. PLoS One 9:e85021

Butler JS, Lee JH, Skalnik DG (2008) CFP1 interacts with DNMT1 independently of association with the Setd1 histone H3K4 methyltransferase complexes. DNA Cell Biol 27:533-543

Daniel K et al (2011) Meiotic homologue alignment and its quality surveillance are controlled by mouse HORMAD1. Nat Cell Biol 13: 599-610

de Massy B (2013) Initiation of meiotic recombination: how and where? Conservation and specificities among eukaryotes. Annu Rev Genet 47:563-599

Eberl HC, Spruijt CG, Kelstrup CD, Vermeulen M, Mann M (2013) A map of general and specialized chromatin readers in mouse tissues generated by label-free interaction proteomics. Mol Cell 49:368 378

Eram MS et al (2014) Trimethylation of histone H3 lysine 36 by human methyltransferase PRDM9 protein. J Biol Chem 289:12177-12188

Flachs P et al (2012) Interallelic and intergenic incompatibilities of the prdm9 (hst1) gene in mouse hybrid sterility. PLoS Genet 8: e1003044

Grey C, Barthes P, Chauveau-Le Friec G, Langa F, Baudat F, de Massy B (2011) Mouse PRDM9 DNA-binding specificity determines sites of histone $\mathrm{H} 3$ lysine 4 trimethylation for initiation of meiotic recombination. PLoS Biol 9:e1001176

Grey C, Baudat F, de Massy B (2009) Genome-wide control of the distribution of meiotic recombination. PLoS Biol 7:e35

Grey $\mathrm{C}$ et al (2017) In vivo binding of PRDM9 reveals interactions with noncanonical genomic sites. Genome Res 27:580-590

Groeneveld LF, Atencia R, Garriga RM, Vigilant L (2012) High diversity at PRDM9 in chimpanzees and bonobos. PLoS One 7:e39064

Hayashi K, Yoshida K, Matsui Y (2005) A histone H3 methyltransferase controls epigenetic events required for meiotic prophase. Nature 438:374-378

Hohenauer T, Moore AW (2012) The Prdm family: expanding roles in stem cells and development. Development 139:2267-2282

Houles T, Rodier G, Le Cam L, Sardet C, Kirsh O (2015) Description of an optimized ChIP-seq analysis pipeline dedicated to genome wide identification of E4F1 binding sites in primary and transformed MEFs. Genomics data 5:368-370

Koh-Stenta X et al (2014) Characterization of the histone methyltransferase PRDM9 using biochemical, biophysical and chemical biology techniques. Biochem J 461:323-334

Kono $\mathrm{H}$ et al (2014) Prdm9 polymorphism unveils mouse evolutionary tracks. DNA Res 21:315-326

Kumar R, Bourbon HM, de Massy B (2010) Functional conservation of Mei4 for meiotic DNA double-strand break formation from yeasts to mice. Genes Dev 24:1266-1280
Lange J et al (2016) The landscape of mouse meiotic double-strand break formation, processing, and repair. Cell 167:695-708 e616

Lee JH, Voo KS, Skalnik DG (2001) Identification and characterization of the DNA binding domain of CpG-binding protein. J Biol Chem 276: 44669-44676

Lim FL, Soulez M, Koczan D, Thiesen HJ, Knight JC (1998) A KRABrelated domain and a novel transcription repression domain in proteins encoded by SSX genes that are disrupted in human sarcomas. Oncogene 17:2013-2018

Lupo A, Cesaro E, Montano G, Zurlo D, Izzo P, Costanzo P (2013) KRAB-zinc finger proteins: a repressor family displaying multiple biological functions. Current genomics 14:268-278

Margolin JF, Friedman JR, Meyer WK, Vissing H, Thiesen HJ, Rauscher FJ (1994) Kruppel-associated boxes are potent transcriptional repression domains. Proc Natl Acad Sci 91(10):4509-4513

Margolin G, Khil PP, Kim J, Bellani MA, Camerini-Otero RD (2014) Integrated transcriptome analysis of mouse spermatogenesis. BMC Genomics 15:39

Moosmann P, Georgiev O, Le Douarin B, Bourquin J-P, Schaffner W (1996) Transcriptional repression by RING finger protein TIF1Â that interacts with the KRAB repressor domain of KOX1. Nucleic Acids Res 24(24):4859-4867

Murton BL, Chin WL, Ponting CP, Itzhaki LS (2010) Characterising the binding specificities of the subunits associated with the KMT2/Set1 histone lysine methyltransferase. J Mol Biol 398(4):481-488

Myers S et al (2010) Drive against hotspot motifs in primates implicates the PRDM9 gene in meiotic recombination. Science 327:876-879

Ohta K, Shibata T, Nicolas A (1994) Changes in chromatin structure at recombination initiation sites during yeast meiosis. EMBO J 13: 5754-5763

Oliver PL et al (2009) Accelerated evolution of the Prdm9 speciation gene across diverse metazoan taxa. PLoS Genet 5:e1000753

Pan J et al (2011) A hierarchical combination of factors shapes the genome-wide topography of yeast meiotic recombination initiation. Cell 144:719-731

Panizza S, Mendoza MA, Berlinger M, Huang L, Nicolas A, Shirahige K, Klein F (2011) Spo11-accessory proteins link double-strand break sites to the chromosome axis in early meiotic recombination. Cell 146:372-383

Parvanov ED, Petkov PM, Paigen K (2010) Prdm9 controls activation of mammalian recombination hotspots. Science 327:835

Parvanov ED et al (2017) PRDM9 interactions with other proteins provide a link between recombination hotspots and the chromosomal axis in meiosis. Mol Biol Cell 28:488-499

Patel A, Horton JR, Wilson GG, Zhang X, Cheng X (2016) Structural basis for human PRDM9 action at recombination hot spots. Genes Dev 30:257-265

Peng H, Begg GE, Schultz DC, Friedman JR, Jensen DE, Speicher DW, Rauscher FJ 3rd (2000) Reconstitution of the KRAB-KAP-1 repressor complex: a model system for defining the molecular anatomy of RING-B box-coiled-coil domain-mediated protein-protein interactions. J Mol Biol 295:1139-1162

Peters AH, Plug AW, van Vugt MJ, de Boer P (1997) A drying-down technique for the spreading of mammalian meiocytes from the male and female germline. Chromosom Res 5:66-68

Powers NR, Parvanov ED, Baker CL, Walker M, Petkov PM, Paigen K (2016) The meiotic recombination activator PRDM9 trimethylates both $\mathrm{H} 3 \mathrm{~K} 36$ and $\mathrm{H} 3 \mathrm{~K} 4$ at recombination hotspots in vivo. PLoS Genet 12:e1006146

Pratto F, Brick K, Khil P, Smagulova F, Petukhova GV, Camerini-Otero RD (2014) DNA recombination. Recombination initiation maps of individual human genomes. Science 346:1256442

Robert $\mathrm{T}$ et al (2016) The TopoVIB-like protein family is required for meiotic DNA double-strand break formation. Science 351:943-949 
Smagulova F, Brick K, Pu Y, Camerini-Otero RD, Petukhova GV (2016) The evolutionary turnover of recombination hot spots contributes to speciation in mice. Genes Dev 30:266-280

Smagulova F, Gregoretti IV, Brick K, Khil P, Camerini-Otero RD, Petukhova GV (2011) Genome-wide analysis reveals novel molecular features of mouse recombination hotspots. Nature 472:375-378

Soh YQ, Junker JP, Gill ME, Mueller JL, van Oudenaarden A, Page DC (2015) A gene regulatory program for meiotic prophase in the fetal ovary. PLoS Genet 11:e1005531

Sommermeyer V, Beneut C, Chaplais E, Serrentino ME, Borde V (2013) Spp1, a member of the Set1 complex, promotes meiotic DSB formation in promoters by tethering histone $\mathrm{H} 3 \mathrm{~K} 4$ methylation sites to chromosome axes. Mol Cell 49:43-54

Stanzione M et al (2016) Meiotic DNA break formation requires the unsynapsed chromosome axis-binding protein $\mathrm{IHO} 1$ (CCDC36) in mice. Nat Cell Biol 18:1208-1220

Sun F et al (2015) Nuclear localization of PRDM9 and its role in meiotic chromatin modifications and homologous synapsis. Chromosoma $124: 397-415$
Thomas JH, Emerson RO, Shendure J (2009) Extraordinary molecular evolution in the PRDM9 fertility gene. PLoS One 4:e8505

Thomson JP et al (2010) CpG islands influence chromatin structure via the CpG-binding protein Cfp1. Nature 464:10821086

Voo KS, Carlone DL, Jacobsen BM, Flodin A, Skalnik DG (2000) Cloning of a mammalian transcriptional activator that binds unmethylated $\mathrm{CpG}$ motifs and shares a CXXC domain with DNA methyltransferase, human trithorax, and methyl-CpG binding domain protein 1. Mol Cell Biol 20:2108-2121

$\mathrm{Wu} \mathrm{H}$ et al (2013) Molecular basis for the regulation of the H3K4 methyltransferase activity of PRDM9. Cell Rep 5:13-20

Wu TC, Lichten M (1994) Meiosis-induced double-strand break sites determined by yeast chromatin structure. Science 263:515-518

Zickler D, Kleckner N (1999) Meiotic chromosomes: integrating structure and function. Annu Rev Genet 33:603-754 